\title{
PENERAPAN STRATEGI PEMBELAJARAN PQ4R (PREVIEW, QUESTION, READ, REFLECT,RECITE, DAN REVIEW) DALAM MENINGKATKAN PRESTASI BELAJAR PAI
}

\author{
Astriani Wangka ${ }^{1}$, Mustahidang Usman ${ }^{2}$ \\ ${ }^{*}$ Pendidikan Agama Islam Fakultas Agama Islam| Unismuh Makassar \\ ${ }^{* 2}$ Pendidikan Agama Islam Fakultas Agama Islam| Unismuh Makassar
}

\begin{abstract}
ABSTRAK
Penelitian ini menggunakan penelitian tindakan kelas atau classroom action research (CAR). Dalam Penerapan strategi pembelajaran (preview, question, read, reflect,recite, dan review) $P Q 4 R$ siswa dituntut untuk lebih kreatif dan aktif dalam membaca dan menyimak, menelaah materi yang disajikan, sehingga kepecayaan dirinya dapat muncul sehingga ia dapat lebih aktif dalam kelas, dapat menumbuhkan rasa percaya diri siswa, sehingga dalam proses belajar mengajar siswa lebih menyenangkan dan lebih serius belajar. Hasil penelitian membuktikan bahwa Penerapan strategi pembelajaran preview, question, read, reflect, recite, dan review (PQ4R) sangat berpengaruh dalam meningkatkan prestasi belajar PAI siswa SMA Neg. 1 Anggeraja, yang ditandai dengan kian meningkatnya hasil belajar siswa dari siklus ke siklus yang lain yakni ketuntasan hasil belajar pada pra siklus 37, 03 $\%$, siklus 1 yakni 44,44\%, dan siklus 2 yakni 81,48\%.
\end{abstract}

Kata Kunci: Strategi Pembelajaran, PQ4R, Prestasi Belajar

\section{ABSTRACT}

This study uses classroom action research or classroom action research (CAR). In the Application of instructional strategies (preview, question, read, reflect, Recite, and review) $P Q 4 R$ students are required to be more creative and active in reading and listening, assessing the material presented, so trust he may appear so that he can be more active in the classroom, can foster self-confidence of students, so that students in the learning process more fun and more serious about learning,. Research shows that learning strategies Implementation preview, question, read, reflect, Recite, and review (PQ4R) is very influential in improving learning achievement of high school students PAI Neg. 1 Anggeraja, characterized by ever increasing student learning outcomes from cycle to another cycle that mastery learning outcomes in precycle $37,03 \%$, ie $44.44 \%$ cycle 1 and cycle 2 which is $81.48 \%$.

Keyword: Learning Strategies, $P Q 4 R$, Achievement 


\section{PENDAHULUAN}

Pendidikan

merupakan

kebutuhan sepanjang hayat. Setiap manusia membutuhkan pendidikan, sampai kapan dan dimanapun ia berada. Pendidikan sangat penting karena tanpa pendidikan manusia akan sulit berkembang dan bahkan akan terbelakang. Menurut Djamarah (2005:22) pendidikan adalah usaha sadar dan bertujuan untuk mengembangkan kualitas.

Adapun pengertian pendidikan menurut Undang-Undang Sistem Pendidikan Nasional No.20 Tahun 2003 adalah usaha sadar dan terencana untuk mewujudkan suasana belajar dan proses pembelajaran agar peserta didik secara aktif mengembangkan potensi dirinya untuk memiliki kekuatan spiritual keagamaan, pengendalian diri, kepribadian, kecerdasan, ahklak mulia, serta keterampilan yang diperlukan dirinya, masyarakat, bangsa dan negara.

Teori belajar menekankan bahwa belajar terdiri atas membangkitan respon dengan stimulus yang pada mulanya bersifat netral atau tidak memadai (Hamalik, 2004:49). Tujuan pembelajaran merupakan salah satu aspek yang perlu dipertimbangkan dalam merencanakan pembelajaran, sebab segala kegiatan pembelajaran muaranya pada tercapainya tujuan tersebut.

Oleh karena itu diperlukan keterampilan memilih dan menggunakan metode mengajar untuk diterapkan dalam sistem pembelajaran yang efektif sehingga hal ini akan membawa siswa ke dalam situasi belajar yang bervariasi dan siswa terhindar dari situasi pembelajaran yang membosankan.
Fungsi pendidikan mengembangkan kemampuan dan membentuk watak serta peradaban bangsa yang bermartabat dalam rangka mencerdaskan kehidupan bangsa, mengembangkan potensi peserta didik agar menjadi manusia yang beriman, bertakwa kepada Tuhan Yang Maha Esa, berahklak mulia, sehat, berilmu, cakap, kreatif, mandiri dan menjadi warga negara yang demokratis serta bertanggung jawab (Muchith, 2007:7).

Menurut Slameto (2003:2) "belajar merupakan suatu proses perubahan yaitu perubahan tingkah laku sebagai hasil dari interaksi dengan lingkungandalam rangka memenuhi kebutuhan hidupnya". Gagasan pendidikan hari ini diarahkan pada pendidikan yang berbasis agama khususnya agama islam dan salah satu solusinya adalah gagasan pendidikan berkarakter yang secara garis besar seiring dan sejalan nilai-nilai pendidikan agama islam.

Strategi pembelajaran PQ4R ini, salah satu strategi yang digunakan dalam pembelajaran untuk membantu siswa mengingat apa yang mereka baca, dan membantu dalam belajar mengajar di kelas yang dilaksankan dengan membaca buku. Kegiatan membaca buku bertujuan untuk mempelajari bab demi bab suatu buku pelajaran. Oleh karena itu, keterampilan pokok yang harus dikembangkan dan dikuasai siswa adalah membaca buku pelajaran pendidikan agama islam dan buku tambahan lainnya.

Thomasalah dan Robinson dalam Trianto, (2007: 147-149) mengungkapkan salah satu strategi yang paling banyak dikenal untuk membantu 
siswa memahami dan mengingat materi yang dibaca adalah strategi PQ4R.

Langkah - langkah yang harus dilakukan dalam startegi pembelajaran PQ4R adalah: (1). Preview, langkah pertama ini dimaksud agar siswa membaca selintas dengan cepat. (2). Question, langkah kedua yaitu mengajukan pertanyaan- pertanyaan pada diri sendiri untuk setiap pasal yang ada pada siswa. (3). Read, yaitu baca buku dan bahan bacaan lainnya dengan efektif, yakni dengan cara, pikiran siswa harus memberi reaksi terhadap apa ynag dibacanya. (4). Reflection (refleksi) dimana menurut Sutarjo (2012 : 97) "refleksi adalah proses pengendapan pengalaman yang telah dipelajari, yang dilakukan dengan cara mengurutkan kembali kejadian-kejadian atau peristiwa pembelajaran yang telah dilaluinya". (5). Recite, pada langkah ke-lima ini, siswa diminta untuk merenungkan (mengingat) kembali informasi yang telah dipelajari dengan menyatakan butir-butir yang penting dengan nyaring dan dengan menanyakan dan menjawab pertanyaan-peryanyaan dan (6). Review, pada langkah terakhir ini siswa diminta untuk membaca catatan singkat (inti sari) yang telah dibuatnya, kemudian siswa diarahkan agar mengulang kembali seluruh isi bacaan bila perlu dan sekali lagi menjawab pertanyaan yang telah dibuatnya.

$$
\text { Strategi pembelajaran }
$$

Preview, Question, Read, Reflect, Recite, Dan Review (PQ4R), guru sebagai pengajar mampu menciptkan pembelajaran aktif, kreatif dan inovatif, karena tidak dapat dipungkiri, tujuan pembelajaran yang sesungguhnya adalah bagaimana mentransformasikan ilmu kepada siswa agar dapat memahami pelajaran dengan baik.

\section{METODOLOGI PENELITIAN}

Penelitian ini menggunakan penelitian tindakan kelas atau Classroom Action Research (CAR), dengan jenis penelitian kualitatif, kemudian dianalisis dengan menggunakan deskriftif kualitatif Penelitian ini berlokasi di SMA Neg. 1 Anggeraja kab. Enrekang dan objek penelitian ini adalah guru dan siswa kelas XI IPA2 SMA Neg.1 Anggeraja Kab. Enrekang.

Adapun variabel penelitiannya yaitu Variabel independen (variable bebas) yakni penerapan strategi pembelajaran PQ4R (Preview, Question, Read, Reflect, Recite,dan Review) dalam hal ini dinyatakan sebagai simbol (x). Variabel dependen (variabel terikat ) yakni meningkatkan prestasi belajar PAI yang dinyatakan sebagai symbol (y). Populasi penelitian, guru 69 Orang dan siswa 136 sedangkan sampel yang diambil berjumlah 31 orang terdiri dari 9 orang guru dan 22 orang siswa.

Data yang dikumpulkan harus memenuhi syarat yaitu: objektif, relevan, actual, dan representatil. Data objektif adalah data yang diperoleh dari penelitian lapangan harus ditampilkan dan dilaporkan apa adanya.

Dalam penelitian ini digunakan ada dua jenis metode yaitu pengumpulan data dan metode analisis data untuk memperoleh data di lapangan, penelitian menggunkan 4 cara yaitu: Observasi, kusioner ( angket), wawancara dan dokumentasi.

Analisis yang dapat digunakan dalam penelitian ini adalah analisis deskriftif kualitatif. Analisis ini dimaksudkan untuk mendeskripsikan semua gejala- gejala yang didapatkan selama penelitian berlangsung. Analisis 
Kualitatif diperlukan pada data hasil observasi, dan angket.

$$
\text { Untuk }
$$

menghitung peningkatan hasil belajar maka persentasenya menggunakan rumus sederhana presentase.

$$
\mathrm{P}(\%)=\frac{F}{N} X \mathbf{1}
$$

Dimana:

$\mathrm{P}=$ Presente

$\mathrm{F}=$ Frekuensi yang Dicari Presentase

$\mathrm{N}=$ Jumlah Subjek

\section{HASIL PENELITIAN}

Adapun objek penelitian ini sebagai berikut.

Tabel 1

\section{Keadaan siswa kelas IPA}

\begin{tabular}{|c|l|l|l|c|}
\hline \multirow{2}{*}{ No } & \multirow{2}{*}{$\begin{array}{c}\text { Guru } \\
\text { dan } \\
\text { Siswa }\end{array}$} & \multicolumn{2}{|c|}{ Jumlah } & \multicolumn{1}{c|}{ Total } \\
\cline { 3 - 5 } 1. & $\begin{array}{l}\text { XI IPA } \\
1\end{array}$ & $\begin{array}{l}9 \\
\text { orang }\end{array}$ & $\begin{array}{l}20 \\
\text { orang }\end{array}$ & $\begin{array}{c}29 \\
\text { orang }\end{array}$ \\
\hline 2. & $\begin{array}{l}\text { XI IPA } \\
2\end{array}$ & $\begin{array}{l}6 \\
\text { orang }\end{array}$ & $\begin{array}{l}21 \\
\text { orang }\end{array}$ & $\begin{array}{c}27 \\
\text { orang }\end{array}$ \\
\hline 3. & $\begin{array}{l}\text { XI IPA } \\
3\end{array}$ & $\begin{array}{l}6 \\
\text { orang }\end{array}$ & $\begin{array}{l}21 \\
\text { orang }\end{array}$ & $\begin{array}{c}27 \\
\text { orang }\end{array}$ \\
\hline 4. & $\begin{array}{l}\text { XI IPA } \\
4\end{array}$ & $\begin{array}{l}6 \\
\text { orang }\end{array}$ & $\begin{array}{l}22 \\
\text { orang }\end{array}$ & $\begin{array}{c}28 \\
\text { orang }\end{array}$ \\
\hline 5. & $\begin{array}{l}\text { XI IPA } \\
5\end{array}$ & $\begin{array}{l}5 \\
\text { orang }\end{array}$ & 24 orang & $\begin{array}{c}29 \\
\text { orang }\end{array}$ \\
\hline \multicolumn{2}{|l|}{ Jumlah } & $\begin{array}{l}\mathbf{3 2} \\
\text { Orang }\end{array}$ & $\begin{array}{l}\mathbf{1 0 8} \\
\text { orang }\end{array}$ & $\begin{array}{c}\mathbf{1 4 0} \\
\text { orang }\end{array}$ \\
\hline
\end{tabular}

1. Strategi Pembelajaran PAI Siswa SMA Neg. 1 Anggeraja Kab. Enrekang

Metode yang sering digunakan guru adalah metode ceramah, metode inilah yang membuat siswa menjadi fakum dan bosan mengikuti pelajaran PAI. Sehingga guru mengalami kendala pada setiap pembelajaran PAI, sikap siswa yang sering acuh, ribut, dan kadang tidak hadir mengikiti pelajaran, akibatnya guru terkadang merasa terganggu dan kesulitan menanganinya, yang berakibat menurunnya prestasi belajar siswa. Prestasi belajar siswa dapat di gambarkan pada table berikut:

Table 2

\section{Presentase Hasil Belajar Siswa Kelas XI IPA2 Pra Siklus}

\begin{tabular}{|c|c|c|l|l|l|}
\hline $\begin{array}{c}\text { N } \\
\text { o }\end{array}$ & $\begin{array}{c}\text { Sikl } \\
\text { us }\end{array}$ & \multicolumn{3}{|c|}{ Jumlah Ketuntasan } \\
\hline & & $\begin{array}{l}\text { Tunt } \\
\text { as } \\
\text { (Sis } \\
\text { wa) }\end{array}$ & $\begin{array}{l}\text { Persen } \\
\text { tase } \\
(\%)\end{array}$ & $\begin{array}{l}\text { Bel } \\
\text { um } \\
\text { Tun } \\
\text { tas }\end{array}$ & $\begin{array}{l}\text { Persen } \\
\text { tase } \\
(\%)\end{array}$ \\
\hline & $\begin{array}{l}\text { Pra } \\
\text { Sikl } \\
\text { us }\end{array}$ & 10 & 37,03 & 17 & 62,96 \\
\hline
\end{tabular}

Dari tabel di atas dapat dihitung presentase ketuntasan dengan menggunakan rumus sebagai berikut: Tuntas $(\%)=\frac{F}{N} X 100=\frac{1}{2} \times 100=$ 37,03 Belum Tuntas $(\%)=\frac{F}{N} X 100=$ $\frac{1}{2} X 100=62,96$

Dari presentase di atas yang kita melihat bahwa hasil belajar atau prestasi belajar yang dicapai siswa masih sangat jauh dari harapan. Strategi pembelajaran merupakan penunjang pokok dalam hasil belajar siswa. Sebagian guru sering menggunakan strategi pembelajaran digunakan dalam pembelajaran PAI yakni strategi pembelajara 
CTL(Contextual Teaching and Learnig), yang hampir sejalan dengan penggunaan strategi PQ4R yang menekatkan keterlibatan siswa dalam proses pembelajran. Namun sebagian guru hanya menggunakan metode ceramah yang sama sekali tidak dapat mengaktifkan siswa.

\section{Penerapan Strategi Pembelajan Preview, Question, Read, Reflect,Recite, dan Review (pq4r) Siswa SMA Neg. 1 Anggeraja Kab.Enrekang}

Sebelum melakukan penelitaian tindakan kelas, peneliti melakukan koordinasi dengan guru mata pelajaran PAI kelas XI IPA 2. Penelitii berkedudukan sebagai observer (pengamat) untuk mengamati guru dalam menerapakan strategi pembelajan PQ4R yang telah ditentukan dari awal, guru tetap menjadi sumber belajar siswa dalam kelas.

Proses pembelajaran pada siklus 1 dimulai dengan menyampaikan tujuan pembelajaran kepada siswa dan gambaran materi tentang penyelenggaran jenazah. Guru menerangkan materi hanya garis besarnya saja kemudian pengamat membagikan materi bacaan kepada siswa. Kemudian pengamat menjelaskan langkah-langkah penerapan strategii pembelajaran PQ4R yang akan diterpakan dalam proses belajar tersebut.

Table 3
Hasil Belajar PAI kelas XI IPA3
Siklus 1
\begin{tabular}{|c|c|c|c|c|c|}
\hline \multirow{3}{*}{ N } & Sikl & \multicolumn{4}{|c|}{ Jumlah ketuntasan } \\
\cline { 3 - 6 } o & us & Tun & Persen & Bel & Persen \\
& tas & tase & um & tase \\
(sis & $(\%)$ & tunt & $(\%)$ \\
\hline
\end{tabular}

\begin{tabular}{|c|c|c|c|c|c|}
\hline & & wa) & & as & \\
\hline 1. & $\begin{array}{c}\text { Sikl } \\
\text { us } \\
1\end{array}$ & 12 & 44,44 & 15 & 55,55 \\
\hline
\end{tabular}

Dari tabel di atas dapat dihitung presentase ketuntasan dengan menggunakan rumus sebagai berikut:

Tuntas $(\%)=\frac{F}{N} \times 100=\frac{1}{2} \times 100=$ 44,44 Belum Tuntas $(\%)=\frac{F}{N} X 100=$ $\frac{1}{2} X 100=55,55$

Penerapan strategi pembelajaran PQ4R pada siklus 1 ini sudah dapat menaikkan prestasi belajar siswa dalam belajar PAI siswa SMA neg. 1 anggeraja, dimana kita lihat bahwa pada pra siklus presentase ketuntasan hasil belajar siswa hanya mencapai 37,03\% dan pada siklus 1 pada saat penerapan strategi pembelajaran PQ4R ketuntasan hasil belajar siswa sudah mencapai $44,44 \%$.

b. Pengaruh Strategi Pembelajaran Preview, Question, Read, Reflect, Recite, dan Review (PQ4R) Terhadap Peningkatan Prestasi belajar PAI siswa siswa SMA Neg. 1 Anggeraja Kab. Enrekang.

Table 4

Hasil belajar PAI kelas XI IPA2 siklus 2

\begin{tabular}{|c|c|c|c|c|c|}
\hline \multirow{2}{*}{$\begin{array}{c}\text { N } \\
\text { o }\end{array}$} & $\begin{array}{c}\text { Sikl } \\
\text { us }\end{array}$ & $\begin{array}{c}\text { Tunt } \\
\text { as } \\
\text { sis } \\
\text { wa) }\end{array}$ & $\begin{array}{c}\text { Persen } \\
\text { tase } \\
(\%)\end{array}$ & $\begin{array}{c}\text { Bel } \\
\text { tumt } \\
\text { as }\end{array}$ & $\begin{array}{c}\text { Perse } \\
\text { ntase } \\
(\%)\end{array}$ \\
\hline 1. & $\begin{array}{c}\text { Sikl } \\
\text { us 2 }\end{array}$ & 22 & 81,48 & 5 & 18,51 \\
\hline
\end{tabular}


Dari tabel diatas dapat dihitung presentase ketuntasan dengan menggun akan rumus sebagai berikut:

Tuntas $(\%)=\frac{F}{N} X 100=\frac{Z}{2} X 100=81,48$

Belum Tuntas $(\%)=\frac{F}{N} X 100=$ $\frac{5}{2} X 100=18,51$

Berdasarkan presentase pada hasil belajar siswa pada siklus 2 ini dapat diambil kesimpilan bahwa penerapan strategi pembelajaran dapat berpengaruh pada peningkatkan prestasi belajar siswa, yang dapat ditandai dengan makin meningkatnya hasil belajar siswa,dimana pada pra siklus ketuntasan siswa hanya sekitar 37,03\%, pada siklus 1 sekitar $44,44 \%$, dan pada siklus 2 ketuntasan hasil belajar siswa hampir sempurna yakni 81,48\%.

Table 5

Siswa yang menyukai strategi pembelajaran yang diterapkan guru PAI

\begin{tabular}{|c|c|c|c|}
\hline No. & $\begin{array}{c}\text { Alternatif } \\
\text { Jawaban }\end{array}$ & $\begin{array}{c}\text { Frekue } \\
\text { nsi }\end{array}$ & Persentase \\
\hline 1. & Ya & 4 & $14,81 \%$ \\
\hline 2. & $\begin{array}{c}\text { Kadang- } \\
\text { kadang }\end{array}$ & 23 & $85,18 \%$ \\
\hline 3. & Tidak & - & - \\
\hline \multicolumn{2}{|c|}{ Jumlah } & 27 & $99,99 \%$ \\
\hline
\end{tabular}

Tabulasi angket no.1

Dari tabulasi angket dapat diketahui bahwa siswa yang menyukai strategi pembelajaran yang telah diterapkan guru selama ini sebanyak 4 siswa $(14,81 \%)$, dan yang menyatakan tidak sebanyak 0 siswa (0\%), dan yang menyatakan kadang- kadang sebanyak 23 siswa $(85,18 \%)$. Sehingga peneliti mengambil kesimpulan bahwa siswa terkadang siswa tidak senang dengan strategi pembelajaram yang digunakan guru.

Table 6

Stretegi Pembelajaran yang diterapkan guru dapat mengaktifkan siswa dalam kelas

\begin{tabular}{|c|c|c|c|}
\hline No & $\begin{array}{c}\text { Alternati } \\
\mathrm{f} \\
\text { Jawaban }\end{array}$ & $\begin{array}{c}\text { Frekuens } \\
\mathrm{i}\end{array}$ & $\begin{array}{c}\text { Persentas } \\
\mathrm{e}\end{array}$ \\
\hline 1. & Ya & & \\
\hline 2. & $\begin{array}{c}\text { Kadang- } \\
\text { kadang }\end{array}$ & 25 & $92,59 \%$ \\
\hline 3. & Tidak & 2 & $7,40 \%$ \\
\hline & Jumlah & 27 & $99,99 \%$ \\
\hline
\end{tabular}

Dari table di atas dapat diketahui bahwa respon menjawab "ya" sebanyak 0 siswa, "tidak" sebanyak 2 siswa (7,40\%), dan yang menjawab "kadangkadang" sebanyak 25 siswa $(92,59 \%)$. Peneliti dapat mengambil kesimpulan bahwa strategi yang digunakan guru dalam proses pembelajaran belum mengaktifkan siswa dalam proses pembelajaran.

\section{Table 7}

Strategi Pembelajaran PQ4R meningkatkan prestasi belajar siswa

\begin{tabular}{|c|c|c|c|}
\hline No. & $\begin{array}{c}\text { Alternatif } \\
\text { Jawaban }\end{array}$ & $\begin{array}{c}\text { Frekue } \\
\text { nsi }\end{array}$ & $\begin{array}{c}\text { Persent } \\
\text { ase }\end{array}$ \\
\hline 1. & Ya & 25 & $92,59 \%$ \\
\hline 2. & $\begin{array}{c}\text { Kadang- } \\
\text { kadang }\end{array}$ & - & \\
\hline 3. & Tidak & 2 & $7,40 \%$ \\
\hline & Jumlah & 27 & $99,99 \%$ \\
\hline
\end{tabular}

Dari tabulasi angket di atas penulis dapat menjabarkan presentase bahwa yang menjawab "ya" sebanyak 25 siswa (92,59\%), "tidak" sebanyak 2 siswa $(7,40)$ dan "kadang- kadang" sebanyak 0 siswa, sehingga penulis dapat menyimpulkan bahwa penggunaan 
strategi pembelajaran PQ4R dapat meningkatkan prestasi belajar siswa, ini sejalan dengan adanya peningkatan hasil belajar siswa pada saat proses pembelajaran yang telah dilakukan sebelumnya.

Penerapan strategi pembelajaran PQ4R sangat berpengarauh pada peningkatan prestasi belajar siswa karena dalam penerapan strategi pembelajaran PQ4R sangat menunjang kinerja guru dalam proses belajar mengajar (PBM).

Guru di dalam penerapan strategi ini harus memiliki kreatifitas tinggi dalam penyampaian meteri untuk membengkitkan semangat belajar siswa sehingga dalam proses pembelajaran siswa tidak lagi canggung unjuk diri mengembangkan potensi dirinya di dalam kelas. Karena dalam penerapan strategi pembelajaran ini, tugas pokok siswa memiliki kreativitas tinggi atau kemampuan dalam membaca dan menelaah sehingga siswa dapat lebih aktif dalam kelas, baik dalam hal bertanya maupun menyampaikan pendapatnya yang berkaitan dengan materi pembelajaran yang sedang dihadapi.

Penerapan strategi PQ4R merupakan strategi yang baru bagi siswa dan belum pernah didapatkan sebelumnaya sehingga tugas pokok guru disini adalah menumbuhkan minat belajar siswa pada mata pelajaran PAI terutama membaca, karena dalam penerapan strategi ini menuntut siswa untuk memilki keterampilan membaca yang baik pada materi yang diberikan guru. Sehingga siswa dapat dengan percaya diri dalam mengajukan pendapatnya, bertanya dan menjawab pertanyaan dari teman sendiri sihingga meningkatkan peran aktif siswa dalam proses pembelajaran.

Keaktifan siswa dalam proses penerapan strategi pembelajaran PQ4R sangat mempengaruhi peningkatan prestasi belajar siswa, hal ini terbukti dengan meningkatnya hasil belajar siswa dari pra siklus ke siklus 1 dan terakhir siklus 2 yakni pada pra siklus ketuntasan hasil belajar siswa mencapai 37,03\%, siklus 1 mencapai $44,44 \%$, dan pada siklus 2 ketuntasan hasil belajar siswa $81,48 \%$. Jadi peneliti berkesimpulan bahwa penerapan strategi pembelajaran preview, question, read, reflect, recite, dan review (PQ4R) dapat meningkatkan hasil belajar PAI siswa SMA Neg. 1 anggeraja Kab. Enrekang.

\section{PENUTUP}

Berdasarkan hasil pengamatan yang dilkukan oleh peneliti sebagai oabserver maka peneliti daoat mengukiaambil kesimpulan bahwa:

1. Strategi pembelajaran yang digunakan guru pada saat pembelajaran PAI SMA neg. 1 Anggeraja disesuaikan dengan materinya sebagai contoh pada saat materi penyelenggaraan jenazah stretegi yang digunakan adalah demonstrasi dan metode ceramah. Minat belajar siswa pada saat belajar PAI dengan menggunkan metode ceramah tidak mebuat siswa aktif malah mebuat siswa menjadi bosan dalam kelas atau seringkali acuh, ribut, bahkan sering bolos karena kurangnya minat belajar PAI, yang 
berakibat berkurangnya prestasi belajar siswa.

2. Penerapan strategi pembelajaran PQ4R dapat menagaktifkan siswa dalam kelas dan berani menyampaikan intisari dari materi yang disajikan serta dapat lebih percaya diri dalam bertanya dan menyampaikan pendapat, baik itu bertanya maupun menjawab pertanyaan dari guru maupun dari siswa itu sendiri.

3. Setelah diadakan penelitian dengan menggunakan strategi pembelajaran PQ4R, maka pengaruh strategi pembelajaran PQ4R yakni mampu meningkatkan minat belajar, dan keaktifan siswa dalam pelajaran yang ditandai dengan meningkatnya hasil belajar PAI siswa SMA neg. 1 Anggeraja.

\section{DAFTAR PUSTAKA}

Adisusilo, Sutarjo.2013.Pembelajaran Nilai Karakter Konstruktivisme Dan VCT Sebagai Inovasi Pendekatan Pembelajaran Afektif. Jakarta:PT.Rajawali Pers

Al Barry, M. Dahlan. 1994. Kamus Modern Bahasa Indonesia. Yogyakarta: Arkala

Asril, Zainal.2012. Micro Teaching: Disertai Denga Pedoman Pengalaman Lapangan. Jakarta: Rajawali Pers

Bahri Djamarah, Syiful dan Asuan Zaid. 2010. Strategi Belajar Mengajar. Jakarta : PT. Rineka Cipta

Darmansyah.2010. Strategi Pembelajran Menyenangkan dengan Humor. Jakarta: Bumi Aksara
Darmadi, Hamid. 2011. Metode Penelitian Pendidikan. Bandung: Alfabeta

Departemen Agama RI. 2006 UndangUndang dan Peraturan Pemerintah RI Tentang Pendidikan . Jakarta :Dirjen Pendidikan Islam

Departemen Agama RI. 2009. AlQur'an dan Terjemahnya. Bandung : PT sigma examedia arkanleema

Departemen pendidikan nasional. 2005. Kamus besar bahasa Indonesia. Jakarta : Balai Pustaka

Hasibah. 2012. Efektifitas Pembelajaran Menulis Paragraf Argumentasi Berdasarkan Pendekatan Terbuka Terakhir (Open-Ended Approach) Siswa Kelas X Sma Muhammadiyah Kabupaten Selayar. Makassar: UNISMUH

Iskandar. 2012. Psikologi Pendidikan Sebuah Orientasi Baru. Jambi: Referensi

Kunandar.2012. Langkah Mudah Penelitian Tindakan Kelas Sebagai Pengembangan Propesi Guru. Jakarta: PT. Rajawali Pers

Munarfah, Andi dan Mahammad Hasan.2009. Metode Penelitian. Jakarta:Cv. Pratika Akasara Semesta

Nata, Abuddin.2011. Prespektif Islam Tentang Strategi Pembelajaran. Jakarta : Kencana 
Purwanto,Ngalim. 2011. Psikologi

Pendidikan. Bandung: PT.

Remaja Rosdakarya

Rusman. 2012. Model- Model Pembelajaran Mengembangkan Propesional Guru. Jakarta: Rajawali Pers

Tohirin. 2011. Psikologi Pembelajaran Pendidikan Agama Islam. Jakarta: Rajawali Pers

Trianto.2007. model- model pembelajaran inovatif berorientasi konstruktivistik.

Universitas Muhammadiyah Makassar.2008. Pedoman Penulisan Skripsi. Fakultas Agama Islam.

UU. Sisdiknas No. 20 tahun 2003 